\title{
Cadastro Ambiental Rural frente aos remanescentes vegetais nativos das pequenas propriedades rurais do município de Pelotas - RS
}

\author{
Rural Environmental Registration of the native vegetable remaining of the small \\ rural properties in the city of Pelotas - Rio Grande do Sul state
}

Daiana Fonseca Bierhals' ${ }^{\mathrm{I}}$ Bárbara de Lima Corrêa ${ }^{\mathrm{II}}$, Tirzah Moreira SiqueiraIII

\begin{abstract}
Resumo
A inquietação com a proteção do meio ambiente e com a conservação dos seus recursos é progressiva, majoritariamente por causa do cenário futuro de insuficiência dos mesmos. Surgiram então, no Brasil, os Códigos Florestais, os quais se destinam ao anteparo dos recursos vegetais e hídricos brasileiros. O atual Código Florestal (Lei 12.651/12) instituiu o Cadastro Ambiental Rural, instrumento indispensável na obtenção e no registro dos elementos ambientais de todos os imóveis rurais do país. Diante desse quadro, o referido trabalho propôs-se a coletar e a utilizar os dados ambientais de 100 pequenos imóveis rurais registrados na Secretaria de Desenvolvimento Rural do Município de Pelotas. Esses dados foram utilizados para analisar a conformidade dessas propriedades com o presente Código Florestal, equiparando-o com os códigos precedentes. Avaliaram-se os dados das Áreas de Preservação Permanente pela extensão dos cursos d'água e das nascentes e as informações das áreas de Reserva Legal. O desfecho demonstrou que boa parte das propriedades rurais mensuradas se encontra em conformidade com a legislação Florestal vigente. Verificou-se, além disso, que o atual Código Florestal ocasiona uma preservação dos recursos naturais inferior ao Código anterior, tanto para as Áreas de Preservação Permanente, quanto para a Reserva Legal. Isso ocorre porque grande parte das propriedades é classificada como área consolidada, o que ocasiona uma redução significativa das áreas de vegetação nativa determinada para a composição dessas áreas.
\end{abstract}

Palavras-chave: Código Florestal; Área de Preservação Permanente; Reserva Legal; Imóveis rurais

\begin{abstract}
The concern about the protection of the environment and the conservation of its resources is progressive, mainly because of the future scenario of its insufficiency. That is why Forest Codes were created in Brazil, destined to the protection of the Brazilian vegetation and the water resources. The current Forest Code (Law 12.651/12) created the Rural Environmental Registry, an indispensable instrument for obtaining the environmental elements of all rural properties in the country. In the view of this situation, this work proposed to collect and use the environmental data of 100 small rural properties registered in the Rural Development Bureau of the Municipality of Pelotas, obtained through the Rural Environmental Registry, to analyze the compliance of these properties with the present Forest Code, matching it with the predecessor code. The data of the Permanent Preservation Areas was evaluated by the extension of the water courses and springs and the information of the Areas of Legal Reserve. The conclusion showed that most of the rural properties measured are in compliance with the legislation of the current Forest Code. It was also verified that the current Forest Code causes a lower preservation of natural resources than the previous Code, both for the Permanent Preservation Areas and for the Legal Reserve. This event happens because most of the properties are classified as consolidated areas, which results in a significant reduction of the native vegetation ones determined for the composition of these areas.
\end{abstract}

Keywords: Forest Code; Permanent Preservation Area; Legal Reserve; Rural properties

Engenheira Sanitarista e Ambiental, Mestranda no Programa de Pós-Graduação em Sistemas de Produção Agrícola Familiar, Departamento de Fitotecnia, Universidade Federal de Pelotas, Av. Eliseu Maciel, S/N, CEP 96160-000, Capão do Leão (RS), Brasil. daiana.fb@hotmail.com (ORCID: 0000-0001-5149-7967)

II Engenheira Sanitarista e Ambiental, Mestranda no Programa de Pós-Graduação em Recursos Hídricos, Centro de Desenvolvimento Tecnológico, Universidade Federal de Pelotas, Rua Gomes Carneiro, 1, CEP 96010-610, Pelotas (RS), Brasil. barb.lima.correa@gmail.com (ORCID: 0000-00018029-3285)

III Engenheira de Bioprocessos e Biotecnologia, Drª ., Professora do Centro de Engenharias, Universidade Federal de Pelotas, R. Benjamin Constant, 989, CEP 96010-020, Pelotas (RS), Brasil. tirzahsiqueira@hotmail.com (ORCID: 0000-0002-6576-0217) 


\section{Introdução}

Com o objetivo de proteger os recursos naturais que fazem parte do meio ambiente, o Código Florestal brasileiro está entre as principais ferramentas jurídicas que compõem a legislação ambiental no país com esse fim. Sua primeira versão foi sancionada em 1934, seguida pela segunda edição do código que passou a vigorar em 1965, pela Lei no 4.771, a qual aumentou a política de proteção e de conservação da flora, além de estabelecer as Áreas de Preservação Permanente (APP) e a Reserva Legal (RL) (LEHFELD; CARVALHO; BALBIM, 2015).

O “Novo" Código Florestal foi sancionado em 2012, por meio da Lei no 12.651, sendo essa a sua terceira versão, cujo objetivo é a proteção e o uso sustentável das florestas e da vegetação nativa, em equilíbrio com o desenvolvimento sustentável. A Lei institui normas gerais para as Áreas de Preservação Permanente e para as áreas de Reserva Legal, para a fiscalização de produtos de origem florestal e proteção das florestas, utilizando-se de artifícios econômicos a fim de atingir seus propósitos (BRASIL, 2012a).

Ele exige, ao proprietário/possuidor da propriedade rural, a realização do Cadastro Ambiental Rural (CAR), o qual é um registro eletrônico com os dados ambientais dos imóveis rurais que irá compor um banco de informações de âmbito nacional (Sistema Nacional de Informação sobre o Meio Ambiente - SINIMA). De acordo com Laudares, Silva e Borges (2014), o CAR é um sistema de avaliação mais eficaz do que a declaração feita por meio de cartórios e capaz de reduzir o teor burocrático do cadastramento, ao passo que aumenta sua eficiência. Igualmente, Vanzetto et al. (2017) apontam que a instituição do CAR foi eficiente no processo de cadastramento utilizando o georreferenciamento, além da realização de um paralelo entre o cômputo utilizado no novo e no antigo Código Florestal. No entanto, Tupiassu, Gros-Desormaux e Cruz (2017) afirmam que os dados registrados no CAR podem ter baixa confiabilidade, ocasionando fraudes, uma vez que possuem caráter declaratório.

De acordo com a Lei no 13.887 , de 17 de outubro de 2019, os proprietários/possuidores de imóveis rurais terão direito a ingressar no Programa de Regularização Ambiental (PRA) se realizarem a inscrição no CAR até dia 31 de dezembro de 2020. A implementação do PRA é de competência da União, dos Estados e do Distrito Federal, devendo os últimos dois normatizar de maneira mais específica, conforme $\S 1^{\circ}$ do art. 59 do Código Florestal (BRASIL, 2018; 2019).

O sistema de cadastramento do CAR é uma ferramenta para a análise que envolve o uso dos recursos naturais, por meio da delimitação das Áreas de Preservação Permanente (APP) e Reserva Legal (RL), principalmente (LAUDARES; SILVA; BORGES, 2014). Além disso, o novo Código Florestal destaca que, para supressão de vegetação nativa voltada ao uso alternativo do solo, deve ser realizado o cadastramento da propriedade no CAR (art. 26), sendo ele exigido para todas as propriedades rurais (art. 29). Vale ressaltar a grande importância da vegetação nativa para proteção do ecossistema, visto que sua supressão pode causar isolamento reprodutivo de várias espécies, tanto da fauna quanto da flora, sendo ponto principal no trabalho de Brancalion et al. (2016), os quais realizaram uma análise crítica referente à Lei de Proteção da Vegetação Nativa (LPVN) de 2012.

A lei estipula que o proprietário que realizar o CAR e adotar o Programa de Regularização Ambiental (PRA) não será autuado por irregularidades cometidas na RL ou na APP antes de 22 de julho de 2008; além disso, aqueles que assinarem o termo de compromisso, cumprindo as exigências estabelecidas, poderão ter as sanções suspensas e as multas convertidas em serviços de preservação, de melhoria e de recuperação da qualidade do meio ambiente. Em seu aspecto mais polêmico, ela determina as regiões consolidadas que estejam em APP (art. 61) e em RL (art. 66), delimitando as áreas e a maneira como deve ser feita a recomposição da vegetação suprimida, o que, em comparação ao antigo código, pode ser considerado muito menos protetivo. Essas áreas são definidas de acordo com o atual Código Florestal como região protegida, que contenha ou não vegetação nativa, cuja função ambiental é resguardar o meio ambiente nela inserido e garantir a segurança das populações humanas. 
Exemplo de APP de grande importância é a que delimita as áreas adjacentes das nascentes e olhos d'água perenes, indiferentemente do estado topográfico, e que deve ter um diâmetro mínimo de 50 metros. A Lei Federal no 12.727, de 17 de outubro de 2012, inclui no Código Florestal que as faixas marginais desde a borda da calha do leito regular de qualquer curso de água, seja ele perene ou intermitente, exceto os efêmeros, são consideradas como APP.

As nascentes e olhos d'água perenes são de relevância ecológica, contudo sofrem pressão antropogênica devido ao avanço da expansão urbana, industrial e agropecuária. Uma das consequências dessa expansão é a invasão de espécies agressivas, como as gramíneas, que dificultam a regeneração da vegetação delicada presente em um determinado ecossistema, como é possível constatar no trabalho realizado por Silva et al. (2016), que realizaram a avaliação da capacidade de restauração da mata ripária presente em uma nascente já degradada, no município de Lavras, Minas Gerais.

As APPs podem estar assentadas tanto em zona rural quanto em zona urbana, e sua alteração poderá acontecer somente para as situações de utilidade pública, interesse social ou de impacto ambiental reduzido. Azevedo e Oliveira (2014) analisaram as APPs em regiões urbanas e constataram que o Novo Código Florestal viabilizou a utilização dessas áreas de maneira mais acentuada, devido à possibilidade de uso das mesmas, em casos de utilidade pública, interesse social ou de impacto ambiental minimizado. Já Campagnolo et al. (2017), ao verificarem as APPs referentes às matas ciliares que compõem a região da bacia hidrográfica no município de Santa Maria, RS, puderam constatar que as mudanças trazidas pelo Novo Código Florestal foram tanto negativas (reduzindo consideravelmente a mata ciliar que protegeria os corpos hídricos) como positivas (facilitando a realização de sua contabilização).

Em suas Disposições Transitórias, o atual Código Florestal trata essas regiões de maneira distinta. O Código estipula qual deve ser a recomposição mínima imprescindível da vegetação nas faixas marginais das APP de cursos d'água e no entorno de nascentes e olhos d'água perenes em áreas que passaram a ser consideradas consolidadas (BRASIL, 2012a,b). Para tanto, a Lei no 12.651/2012 classifica o tamanho dos imóveis em módulos fiscais, como forma de determinar a faixa de preservação dos recursos florestais. O Módulo Fiscal (MF) é uma unidade de medida de área expressa em hectare (ha) e singular a cada município. Considera-se pequena propriedade ou posse rural aquela que não detenha, a qualquer título, área superior a quatro módulos fiscais (BRASIL, 2006). Na cidade de Pelotas, o valor de um módulo fiscal é 16 ha (BRASIL, 2013).

O tema das áreas consolidadas é controverso, pois significa o indulto, aos proprietários que realizaram desmatamento e ocupações irregulares de áreas não passíveis de uso, antes do dia 22 de julho de 2008. A assinatura do termo de compromisso (art. 59) permite cessar as medidas advindas das infrações precedentes a essa data. Além disso, a recomposição vegetal dessas áreas seguirá as disposições transitórias, mais permissivas, e não as regras gerais (BRASIL, 2012a; LAUDARES; SILVA; BORGES, 2014).

Para áreas de APP cuja alteração na vegetação seja posterior à data de 22 de julho de 2008 , valerão as definições da regra geral. Já para as áreas de APP cuja supressão na vegetação ocorreu antes dessa data (áreas consolidadas), seguirão valendo as regras transitórias, conforme Tabela 1 a seguir, com relação às APPs no entorno de cursos d'água.

O termo Limitador presente na tabela refere-se à recomposição vegetal das APPs presentes no imóvel. De acordo com o código, essa recomposição não pode ultrapassar $10 \%$ da área total do imóvel, para os imóveis com até 2 módulos fiscais. Assim como não deverá extrapolar $20 \%$ se o imóvel possuir entre 2 e 4 módulos fiscais (art. 61-B). Dessa forma, para os imóveis rurais menores, o limitador é benéfico aos seus proprietários/possuidores, tendo em vista o percalço econômico que esse mecanismo ocasiona na abrangência da APP no imóvel (CHIAVARI; LOPES, 2016). 


\section{Tabela 1 - APP em torno de cursos d'água de acordo com a Regra Geral e a Regra Transitória}

Table 1 - APP along water resources according to the General Rule and the Transitional Rule

\begin{tabular}{|c|c|c|}
\hline \multicolumn{3}{|c|}{ Regra Geral - conforme curso d'água } \\
\hline Tamanho do curso d'água & & APP \\
\hline Até 10 metros & & 30 metros \\
\hline Entre 10 a 50 metros & & 50 metros \\
\hline Entre 50 a 200 metros & & 100 metros \\
\hline Entre 200 a 600 metros & & 200 metros \\
\hline Acima de 600 metros & & 500 metros \\
\hline \multicolumn{3}{|c|}{ Regra Transitória - conforme módulos fiscais } \\
\hline Propriedade (em MF) & APP & Limitador \\
\hline Até 1 & 5 metros & $10 \%$ \\
\hline De 1 a 2 & 8 metros & $10 \%$ \\
\hline De 2 a 4 & 15 metros & $20 \%$ \\
\hline Acima de 4 & 20 a 100 metros* & Integral \\
\hline
\end{tabular}

Fonte: Jaguszewski, Gotuzzo e Condorelli (2014)

Em que: *Dependerá da determinação do Programa de Regularização Ambiental (PRA).

É importante destacar que, a partir do Novo Código Florestal, a faixa de preservação de recursos florestais como em APPs não depende mais exclusivamente das características do meio, tais como a largura do rio. Para as regras transitórias leva-se em conta o tamanho das propriedades (em módulos fiscais) que realizaram a supressão de vegetação, bem como a data da supressão. Vanzetto et al. (2017) afirmam que a utilização da medida em módulos fiscais reduz a área de preservação (APP) ao passo que aumenta a área produtiva em termos econômicos, uma vez que, por exemplo, diferentes exigências de reposição poderão ser aplicadas para um mesmo rio, cujas características e interações com o seu entorno não são reguladas pelas limitações físicas das propriedades, mas pelo contexto ambiental em que se inserem.

Outro ponto que contrasta entre os códigos (Lei no 4.771 e Lei ํㅜㄴ 12.651) está relacionado com as características das regiões que devem ser protegidas às margens dos cursos d'água. Pelo antigo código considerava-se o nível mais al to do rio, avaliando o seu período de cheias (e a partir dele era contabilizada a área de APP). Diferentemente, no atual código considera-se a calha do leito regular para a contagem. Ainda que a faixa de reposição permaneça a mesma, a proteção das zonas ripárias ficou reduzida, visto que a metragem da APP inicia-se na margem mais interna dos cursos d'água (LAUDARES; SILVA; BORGES, 2014), permitindo que a exploração do uso do solo, o avanço sobre as zonas de transição entre o meio aquático e terrestre, afete o equilíbrio ecológico natural estabelecido entre os recursos naturais.

A área de Reserva Legal é definida, pela Lei no 12.651/2012, como sendo: área de vegetação nativa situada dentro de uma propriedade ou posse rural, delimitada nos termos do art. 12, com o objetivo de garantir o uso econômico de maneira sustentável dos meios naturais presentes no imóvel rural, além de assegurar a proteção da biota nativa existente (BRASIL, 2012a). Em relação à $\mathrm{RL}$, as duas leis mantiveram as mesmas porcentagens de vegetação nativa a serem conservadas nos imóveis, porém, cabendo um tratamento específico nas Disposições Transitórias. A regulamentação dessas disposições acarreta em uma penosa diminuição na conservação da 
vegetação, em detrimento às preocupações de cunho econômico (RORIZ; FEARNSIDE, 2015).

Na Lei no 4.771/65 existia a exigência de se averbar a RL em cartório; e para o cálculo de sua área não era permitido acrescer a vegetação destinada para a área de APP (BRASIL, 1965). Alterado pelo Novo Código Florestal, o registro da RL é feito através do CAR, e para o cálculo da área é permitido o cômputo das APP (art. 15), sendo proibida, neste caso, a conversão de novas áreas para uso alternativo do solo.

No Boletim Informativo liberado pelo Serviço Florestal Brasileiro (SFB) com dados até o dia 29 de maio de 2018, os valores do CAR para o estado do Rio Grande do Sul indicam que $100 \%$ das áreas passíveis de cadastro foram contabilizadas ao sistema (BRASIL, 2018). Já para a cidade de Pelotas, até a data de 10 de junho de 2018, haviam sido cadastrados 117.527,97 ha (RIO GRANDE DO SUL, 2018).

Em relação ao Bioma Mata Atlântica, deve-se observar diretrizes jurídicas próprias para inscrição no CAR de propriedades inseridas neste bioma. Além disso, para o bioma Pampa, as áreas rurais consolidadas serão tratadas de forma distinta no sistema de cadastro, definidas como áreas rurais consolidadas por supressão de vegetação nativa para uso alternativo do solo e áreas rurais consolidadas por supressão de vegetação nativa com atividades pastoris.

O bioma Pampa está situado, no Brasil, na região sul do estado do Rio Grande do Sul. Ele é caracterizado pela suavidade do relevo, com regiões de vegetação campestre e formação de florestas espessas (SUERTEGARAY; SILVA, 2009). Por mais que a predominância da vegetação seja de campo, o Pampa possui relevante potencial de reserva de matéria carbonácea (FIDELIS; APPEZZATO-DA-GLÓRIA; PFADENHAUER, 2009). Atualmente, o bioma sofre intensa pressão pela introdução de espécies exóticas de cunho madeireiro e pela pecuária (PEREIRA, 2014). Essa tensão gera consequências ambientais e sociais, como é possível constatar no trabalho de Azevedo e Fialho (2015) sobre o conflito entre essas duas atividades na região do Alto Camaquã, RS, sob a visão dos pecuaristas dessa localidade em relação à intensa disseminação das "florestas plantadas”.

O Decreto no $52.431 / 2015$ define como banhados as proporções de terra que apresentam as seguintes características, simultaneamente: solos naturalmente saturados de água por não menos que 150 dias ao ano e a ocorrência espontânea de pelo menos uma das espécies de flora listadas no decreto. As áreas de banhado são de intensa importância ecológica, como a manutenção da biodiversidade e purificação da água. Contudo, estas sofrem pressão antrópica devido à ampliação da urbanização, expansão agrícola e industrial. Dutra e Müller (2017) conceberam a análise dos impactos ambientais em uma região de banhado, no município de Campo Bom (RS), tendo em vista a diminuição da cobertura natural formada anteriormente pelas zonas úmidas do banhado.

Em dezembro de 2015, a justiça concedeu uma liminar contra o Decreto no 52.431/2015. Entre as razões para essa ação, tem-se que toda a extensão de "campo nativo" que é usada como região de pastoreio deve ser apresentada como remanescente de vegetação nativa e não como área consolidada por supressão da vegetação nativa, com atividade de pastoreio, como considera o Decreto do Bioma Pampa.

O Ministério Público do Rio Grande do Sul argumenta que existem evidências científicas de que a presença de gado na região não causa a supressão do campo nativo, tendo em vista as décadas de convívio da vegetação com a atividade pecuária; sendo assim, a área destinada a essa atividade deveria ser computada na contagem da composição da Reserva Legal, nesse caso de $20 \%$ (RIO GRANDE DO SUL, 2016). No entanto, ao considerá-la como remanescente de vegetação nativa, a liminar não leva em conta a degradação gerada pela pecuária, como a erosão e a perda de produtividade, caso feita de maneira incorreta (CORDEIRO et al., 2015). Já considerar os campos do Bioma Pampa como sendo áreas consolidadas, como previsto no Decreto, desobrigaria a sua conservação e manutenção de $20 \%$ de Reserva Legal. Até o momento, a liminar contra o Decreto se encontra em vigência (RIO RANDE DO SUL, 2017).

Diante disso, o presente trabalho teve como intuito avaliar a contribuição do CAR para o conhecimento da situação ambiental dos pequenos imóveis rurais da cidade de Pelotas, Rio 
Grande do Sul, a partir da coleta de dados ambientais de 100 imóveis cadastrados na Secretaria Municipal de Desenvolvimento Rural de Pelotas (SMDR) nos anos de 2015 e 2016, averiguando o impacto ao meio ambiente de acordo com o "Novo" Código Florestal e seu antecessor.

\section{Material e método}

\section{Área de Estudo}

O Município de Pelotas está localizado ao sul do Rio Grande do Sul, às margens do Canal São Gonçalo, com população estimada em 344.385 habitantes, representando a terceira cidade mais populosa do estado e tendo como área territorial aproximadamente $1.610,084 \mathrm{~km}^{2}$ (IBGE, 2017).

Por se encontrar na região sul do estado, sua vegetação predominante está atrelada ao Bioma Pampa, com regiões arbustivas e florestais. Em um estudo realizado por Venzke (2012), foi possível constatar a notória abundância de espécies arbóreas, arborescentes e arbustivas em Pelotas, que pode ser justificada devido a características climáticas da região.

A divisão territorial do município é constituída de nove distritos: Sede, Cascata, Cerrito Alegre, Colônia Z3, Monte Bonito, Quilombo, Rincão da Cruz, Santa Silvana e Triunfo, de acordo

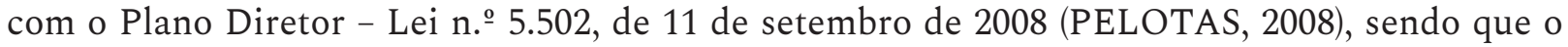
distrito Sede é determinado como zona urbana e os outros distritos, zonas rurais. A Figura 1 mostra a localização geográfica dos distritos dentro do município de Pelotas. Para o trabalho foram avaliadas 100 pequenas propriedades/posses rurais distribuídas de maneira não regular pelos distritos da cidade.

Figura 1 - Município de Pelotas e seus respectivos distritos. Pelotas, 2020

Figure 1 - Municipality of Pelotas and its districts. Pelotas, 2020

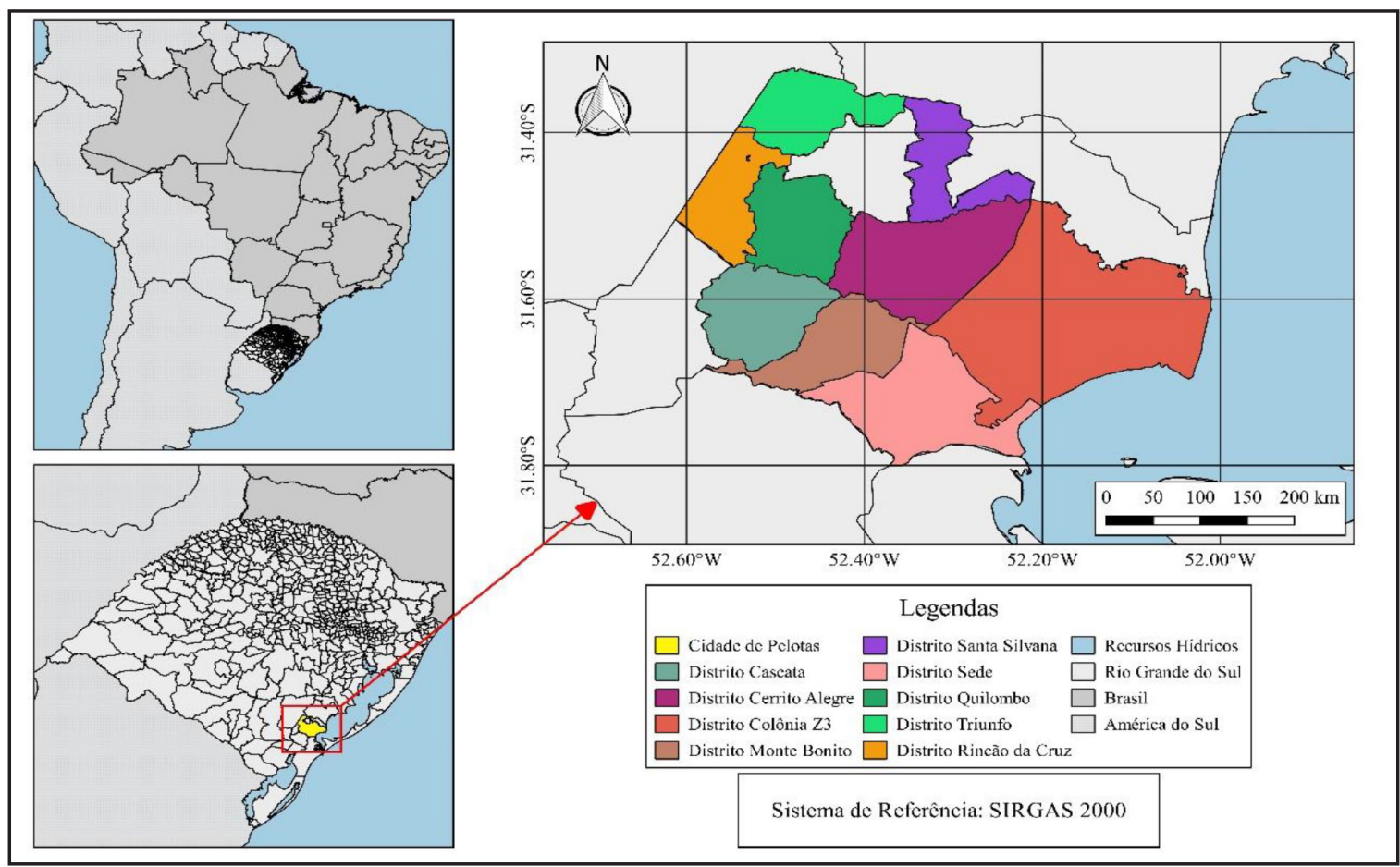

Fonte: Autores (2020) 


\section{Dados do CAR}

Os dados utilizados neste trabalho foram obtidos do Cadastro Ambiental Rural (CAR), referentes à inscrição de 100 imóveis rurais declarados pelos cadastrantes na Secretaria Municipal de Desenvolvimento Rural, SMDR, de Pelotas, Rio Grande do Sul, durante o período de 2015 e 2016. Foram consideradas informações em relação à presença de nascentes ou olhos d'água perenes e suas APPs, Reserva Legal e a quantidade de vegetação selecionada para compô-la, bem como a existência de cursos d'água e suas respectivas APPs.

Os elementos foram selecionados de acordo com a relevância ambiental que simbolizam e também por serem os itens que mais sentiram as alterações na mudança dos Códigos Florestais, sempre levando em consideração as pequenas propriedades rurais.

Através da comparação dos dados e do ajuste deles em relação aos dois códigos, buscouse analisar quantos imóveis estariam de acordo com o código antigo e quantos estão com o novo código, além de qual o impacto real que a mudança do código florestal representou para o meio ambiente.

\section{Resultados e discussão}

As 100 pequenas propriedades/posses rurais do município de Pelotas que foram avaliadas para este estudo estão dispersas pelos distritos da cidade, como pode ser observado na Figura 2 a seguir. O distrito com maior número de imóveis rurais estudados foi o Cascata, com 23 propriedades/posses rurais. Já o distrito Colônia Z3 teve zero propriedades/posses rurais avaliadas.

Figura 2 - Distribuição das propriedades rurais avaliadas de acordo com o distrito. Pelotas, 2016

Figure 2 - Distribution of rural properties evaluated according to the district. Pelotas, 2016

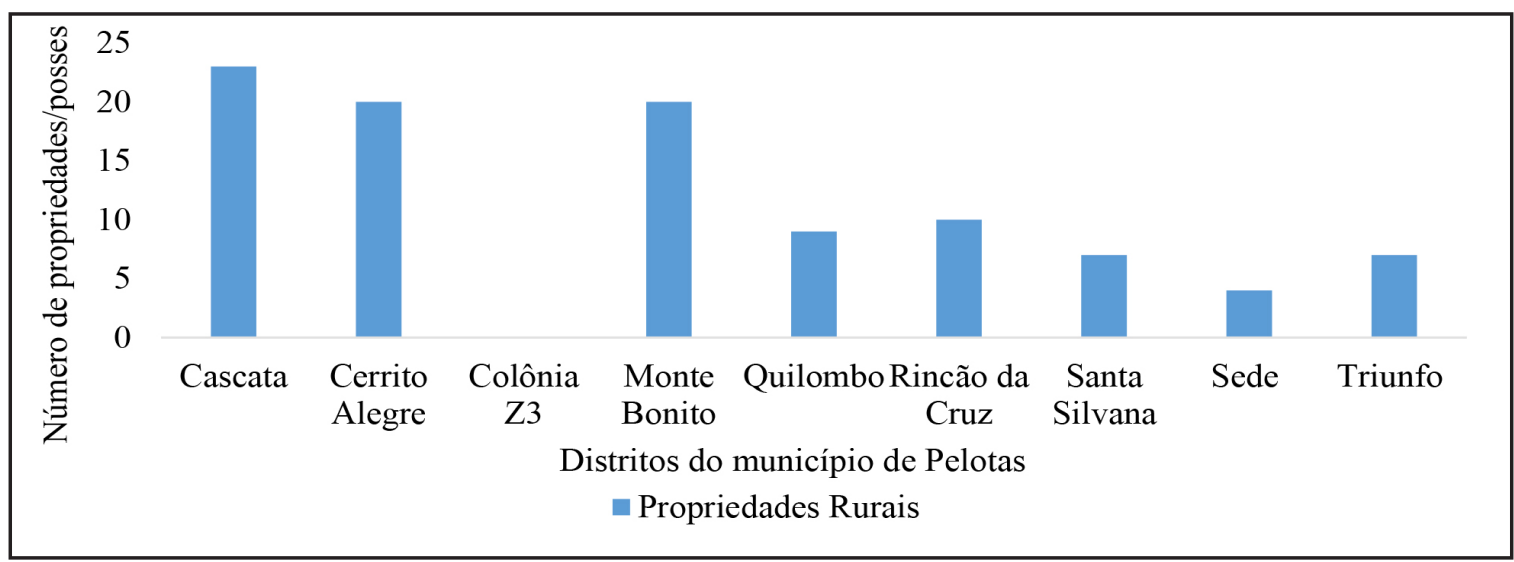

Fonte: Autores (2016)

O valor total em área de todas as propriedades foi de 1.097,4 ha. Desses, $74,85 \%$ foi considerado como área consolidada, $24,12 \%$ como remanescente de vegetação nativa, $0,46 \%$ como infraestrutura pública e $0,57 \%$ como cursos d'água no interior dos imóveis rurais. A Figura 3 a seguir exemplifica de maneira mais clara a distribuição das áreas estudadas de acordo com o uso e a ocupação.

Foi possível verificar que a cobertura do solo do total das propriedades rurais cadastradas está, em sua maior parte, na forma de área consolidada. No trabalho realizado por Wollmann e Bastos (2014), em propriedades da zona rural do município de Porto Alegre, foi obtido resultado 
semelhante de análise dos imóveis rurais, tendo em vista que todos foram considerados como áreas consolidadas. O estudo de Feistauer et al. (2014), realizado em pequenas propriedades rurais ao norte do estado de Mato Grosso, concluiu também que todos os imóveis analisados continham área consolidada.

Figura 3 - Relação das áreas rurais avaliadas de acordo com o seu uso e ocupação. Pelotas, 2016

Figure 3 - Relation of rural areas assessed according to their use and occupation. Pelotas, 2016

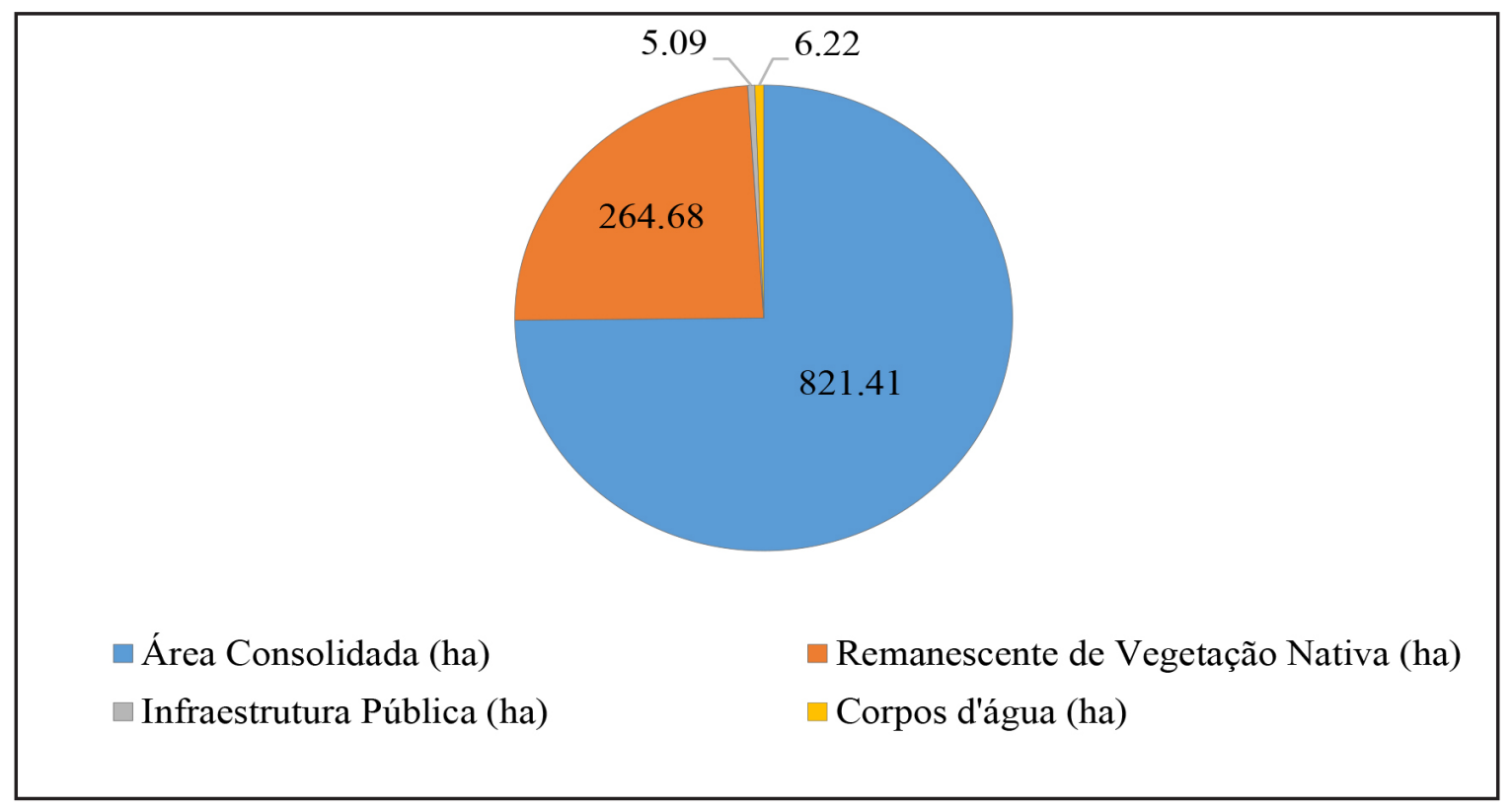

Fonte: Autores (2016)

Tais resultados demonstram que, embora o novo Código Florestal mantenha a regra geral vigente, sua efetiva aplicação é rara em grande parte das propriedades que causaram severa modificação ambiental, especialmente dos recursos florestais, o que pode ser verificado pelo atual cenário de áreas consolidadas existentes e que resulta na aplicação preponderante das regras transitórias e mais permissivas.

Da extensão total das propriedades analisadas, menos de $25 \%$ representa a vegetação nativa. Esse baixo valor indica o processo de perda da vegetação, gerada por alteração antrópica dessas áreas e o desmatamento que essa ação acarreta. Tendo em vista que os imóveis rurais continham, em sua maioria, área consolidada, é possível verificar que ocasionará uma considerável atenuação da proteção da vegetação dessas áreas, refletindo o impacto que as alterações do novo Código Florestal podem acarretar sobre a preservação dos recursos naturais.

A vegetação, principalmente a nativa, garante a estrutura do solo, minimizando os processos erosivos, age ajustando a temperatura local e resguarda o solo de enchentes, além de melhorar a fertilidade dos solos por meio da ciclagem de nutrientes (TAMBOSI et al., 2015). Ela também protege a fauna local e sua diversidade genética, ajudando no controle natural de pragas (BRANCALION et al., 2016). Devido à sua grande importância ambiental, a redução das áreas de vegetação nativa diminui a capacidade de interceptação e infiltração da água, o que ocasiona acréscimo no escoamento superficial e, por consequência, a erosão (TAMBOSI et al., 2015).

$\mathrm{Na}$ Figura 4 é possível verificar a comparação entre as áreas consolidadas e de remanescentes de vegetação nativa dos 100 imóveis cadastrados e considerados neste estudo. 
Figura 4 - Comparação entre área consolidada e remanescente de vegetação nativa de cada propriedade. Pelotas, 2016

Figure 4 - Comparison between the consolidated area and the remaining native vegetation of each property. Pelotas, 2016

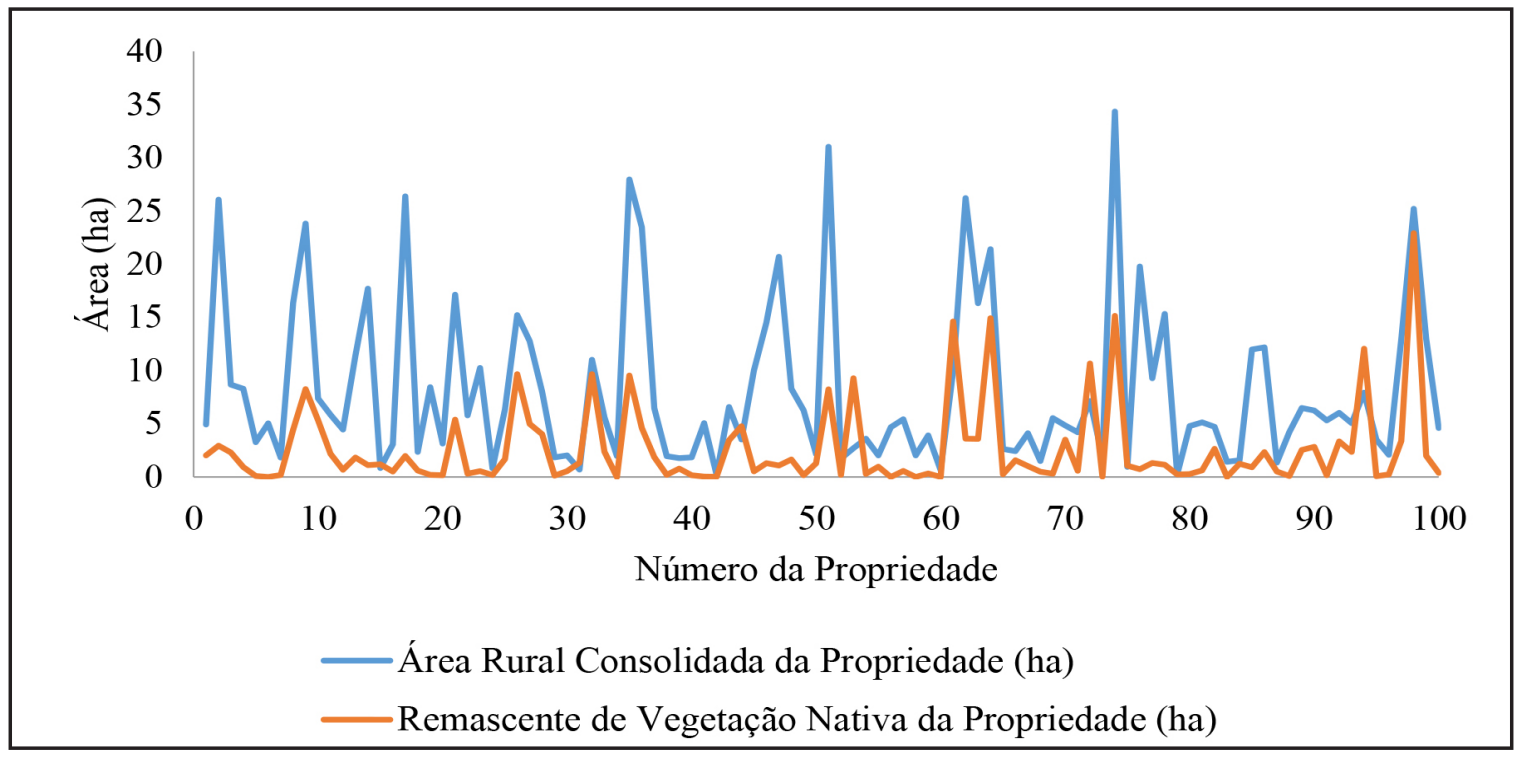

Fonte: Autores (2016)

Pode-se constatar a prevalência das áreas consolidadas sobre as áreas de remanescentes de vegetação nativa, circunstância que influi tanto na biodiversidade do local, como no suporte dos corpos hídricos. A vegetação nativa é aliada do crescimento econômico e melhora a qualidade de vida dos habitantes do meio urbano e rural. Uma economia voltada para a sustentabilidade, feita de maneira que aumente a eficiência dos recursos naturais, garante um bom desenvolvimento econômico e, ao mesmo tempo, resguarda o meio ambiente de danos irreparáveis (CORREIA; DIAS, 2016).

Segundo Silva et al. (2012), manter o remanescente de vegetação nativa nos imóveis vai além de uma discussão ambientalista, visto que a flora é responsável por garantir a qualidade do solo, da água, da biodiversidade, da polinização, além de proteger as culturas e as criações da propriedade. Com isso, pode-se perceber que o aumento da vegetação nativa no imóvel não reduz sua produtividade, e sim assegura que ela se mantenha e se potencialize.

Nesse sentido, em decorrência das alterações sofridas pelo modelo agroexplorador no final da década de 1970 e consequente degradação dos recursos florestais, Pelotas sofreu grande impacto econômico, associado à falência e ao fechamento de diversas grandes indústrias voltadas para o beneficiamento de produtos agrícolas destinados à exportação (SILVA, 2004). Isso corrobora o sentido contraditório apresentado por Silva et al. (2012, p. 78) de pensar que a preservação ambiental, especialmente dos recursos florestais, atuaria contra o desenvolvimento econômico, e que permitir a regularidade de áreas consolidadas configuraria um cenário de perpetuidade dos problemas ambientais atuais existentes e que poderão se agravar ainda mais.

Das regiões que possuem recursos hídricos, pertencentes às propriedades ou próximas a elas e sobre as quais o CAR oferece dados, pode-se enfatizar as áreas de banhado, de corpos hídricos com largura até 10 metros e com largura de 10 a 50 metros e as de nascentes ou olhos d'água perenes.

Nas 100 propriedades avaliadas, encontraram-se 49 nascentes ou olhos d'água perenes, distribuídos entre os 38 imóveis cadastrados. Sendo assim, 62 dos 100 imóveis analisados não 
possuíam essas fontes, fato que pode, hipoteticamente, corroborar com a relação do impacto da intensificação das áreas consolidadas e a redução da vegetação nativa com a diminuição das nascentes.

Assegurar a presença da cobertura vegetal em torno das nascentes é de grande importância, tendo em vista que auxilia a hidrologia do solo, reduzindo o escoamento superficial e intensificando o escoamento subsuperficial, o que minimiza o processo de erosão do solo (FOLLMANN; FOLETO, 2013; LAUDARES; SILVA; BORGES, 2014; TAMBOSI et al., 2015).

O desmatamento está entre os principais causadores de degradação das nascentes. Além disso, os processos de erosão do solo advindos de práticas agressivas de uso da terra, as atividades agropecuárias, os reflorestamentos mal manejados, as queimadas, o descarte de esgoto e lixo urbano e a contaminação dos mananciais intensificam a redução das nascentes (PINHEIRO, 2016; SOARES; TROLEIS, 2017).

Os corpos hídricos declarados dos imóveis rurais cadastrados representaram uma área total de 2,04 ha para banhados (seguidos os critérios de classificação para essas áreas, estabelecidos pelo Decreto Estadual no 52.431 de 2015), 7,97 ha para cursos d'água naturais até 10 metros, 5,79 ha para cursos d'água naturais de 10 a 50 metros, além das 49 nascentes ou olhos d'água perenes. É importante ressaltar que os corpos hídricos analisados se referem tanto aos pertencentes à propriedade quanto ao seu redor.

Além da sua magnitude ecológica, pois resguardam espécies da fauna e da flora, os banhados possuem grande importância no controle de enxurradas e inundações. Por serem regiões que se encontram em zonas mais baixas e com vegetação mais densa, elas absorvem e represam as águas, liberando-as de maneira mais lenta no ambiente. Em períodos de secas, essas características fazem com que os banhados se tornem uma fonte de água para os seres vivos do local (DUTRA; MÜLLER, 2017). Tais características seriam fortemente favorecidas pela manutenção da vegetação nessas propriedades, atuando de forma positiva sobre os problemas ambientais do município de Pelotas, uma vez que a cidade é localizada em terras baixas ou zonas de banhado.

Sob esse aspecto, tem-se um cenário em que a cidade de Pelotas se desenvolveu de forma desordenada às margens de rios e arroios, expandindo-se até suas margens com a consequente supressão de APPs. Esse aspecto do desmatamento e frequente impermeabilização do solo, aliado a outros fatores, tais como a topografia plana da cidade e a disposição inadequada de resíduos sólidos, culminam para o agravamento dos problemas de inundação e poluição resultantes da ausência de vegetação que, de outra forma, poderia também atuar como filtro na dispersão de poluentes.

Da área total dos imóveis rurais, aproximadamente 8 ha representam cursos d'água de até 10 metros de largura (63 cursos d'água), e cerca de 6 ha representam os de largura entre 10 e 50 metros (4 cursos d'água), sendo que estes últimos se encontram fora dos imóveis. Os pequenos cursos d'água (córregos e sangas), muitos deles provenientes de nascentes dos próprios imóveis, são os predominantes.

\section{Área de Preservação Permanente}

Por meio da Figura 5 é possível verificar a comparação entre as áreas totais de APP exigidas pela Lei no $12.651 / 12$, em sua regra geral e regra transitória dos imóveis analisados, além do deficit das propriedades rurais pelas duas regras. Constatou-se que todos os imóveis rurais possuíam deficit de vegetação para compor a APP exigida pelas leis do Novo (regra geral) e do Antigo Código Florestal.

De acordo com a regra geral da lei, que é mais protetiva, o deficit de vegetação dos imóveis cadastrados seria de quase 50 ha. Contudo, todos os imóveis analisados por terem APP em áreas consolidadas, se enquadram nas regras transitórias do "novo" Código Florestal, o que reduz as áreas de APP a serem declaradas, deixando um deficit de pouco mais de 3 ha. 
Figura 5 - Comparação das Áreas de Preservação Permanente. Pelotas, 2016

Figure 5 - Comparison of Permanent Preservation Areas. Pelotas, 2016

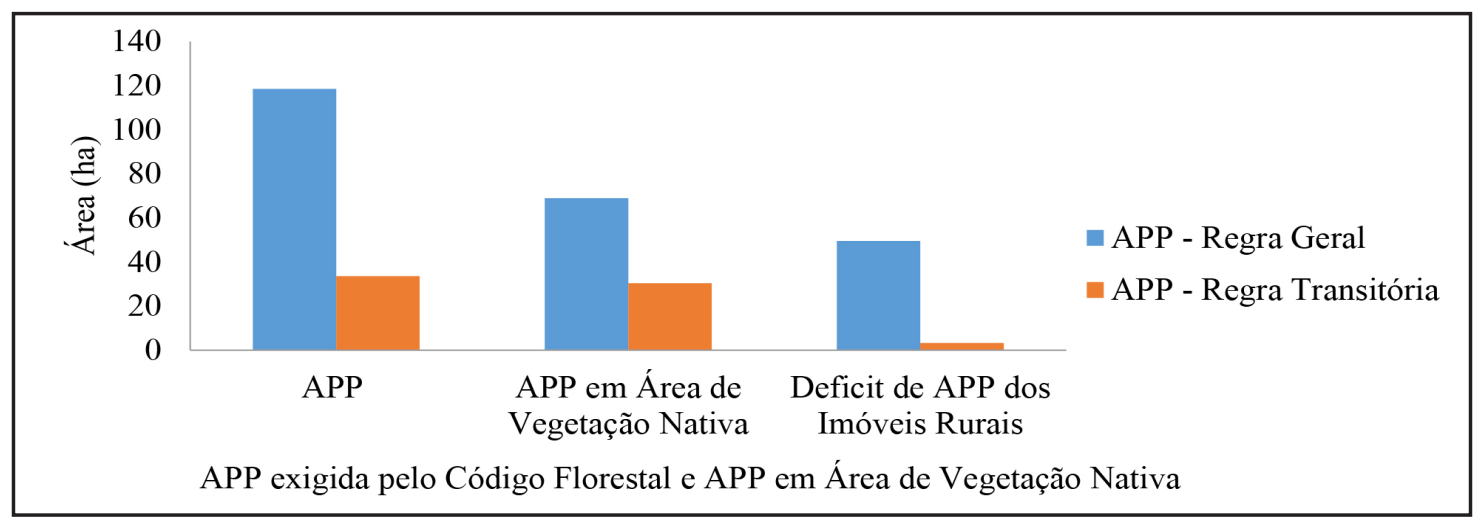

Fonte: Autores (2016)

O paralelo entre as regiões de APP exigidas pelas disposições transitórias e as áreas vegetadas disponíveis para APP indica reduzida diferença entre essas áreas, de aproximadamente 3 ha. Logo, as propriedades têm, em sua maioria, o mínimo de vegetação exigido pelo código vigente para compor as suas APPs segundo a regra transitória. No trabalho realizado por Feistauer et al. (2014) na região de Mato Grosso, apurou-se resultado semelhante, onde mais da metade dos imóveis analisados se encontraram legalmente dentro das exigências de composição da APP, de acordo com as disposições transitórias.

Para as propriedades analisadas, a APP necessária simboliza uma área total de 118,48 ha, segundo a regra geral da lei, mas cai para 33,6 ha, quando considerada pelas disposições transitórias. Dessa maneira, ocorre um deficit de cerca de 90 ha de APP de uma regra para a outra, o qual representa uma ampla área vegetada em torno de áreas vulneráveis e de grande importância ecológica e social, como são os corpos hídricos, e que não necessitará ser recomposta na sua totalidade.

O amparo às APP ao longo das margens de corpos d'água é de primordial importância para a preservação da biodiversidade brasileira, visto que existem sérios impactos negativos da redução dessas áreas, entre eles: a extinção de espécies de plantas e animais; a redução do controle de pragas e da polinização de plantas cultivadas ou selvagens; o assoreamento de cursos d'água; a diminuição do abastecimento de água (TAMBOSI et al., 2015; BRANCALION et al., 2016).

A título de exemplo, na Tabela 2 são apresentados os dados de APP de dois imóveis rurais cadastrados no CAR. Em ambos os imóveis há deficit de APP em relação às disposições gerais da Lei no 12.651/12, sendo que em um dos imóveis registra-se também o deficit de APP das disposições transitórias, tornando o imóvel irregular ambientalmente.

Tabela 2 - Área de Preservação Permanente de dois imóveis rurais. Pelotas, 2016

Table 2 - Permanent Preservation Area of two rural properties. Pelotas, 2016

\begin{tabular}{cccccccc}
\hline & \multicolumn{3}{c}{ Regra Geral (ha) } & \multicolumn{3}{c}{ Regra Transitória (ha) } \\
\hline Prop. & MF & Regra Geral & $\begin{array}{c}\text { Vegetação } \\
\text { Nativa }\end{array}$ & Deficit & $\begin{array}{c}\text { Regra } \\
\text { Transitória }\end{array}$ & $\begin{array}{c}\text { Vegetação } \\
\text { Nativa }\end{array}$ & Deficit \\
\hline $\mathbf{5 1}$ & 2,48 & 8,1707 & 4,0668 & 4,1039 & 3,9216 & 3,1328 & 0,7888 \\
$\mathbf{6 1}$ & 1,54 & 2,7338 & 2,4998 & 0,2340 & 0,7145 & 0,7145 & 0,0000 \\
\hline
\end{tabular}

Fonte: Autores (2016)

Em que: Prop. - propriedade; MF - módulos fiscais. 
$\mathrm{Na}$ propriedade de número 51 (Figura 6a) existem três nascentes que dão origem a três cursos d'água, que deságuam em um quarto curso d'água, o qual é marginal ao imóvel. Em ambas as regras existem deficits de APP, tanto nas nascentes como nos cursos d'água. No imóvel rural há uma grande quantidade de área consolidada (representada pela cor cinza) e pouca vegetação nativa (nesse caso, representada pela cor verde), que se encontra em sua maioria na APP. Durante o cadastro desse imóvel, todas as áreas de vegetação nativa foram destinadas à RL, inclusive a vegetação da APP. A área delimitada pelo tom amarelado representa a APP pela Regra Geral, enquanto a área em tom coral simboliza a APP pela Regra Transitória, podendo perceber a considerável perda de vegetação que a Regra Transitória irá causar.

Figura 6 - Imagens dos imóveis rurais número 51 (a) e 61 (b), no Módulo de Cadastro - CAR, com todas suas áreas delimitadas. Em destaque algumas áreas com deficit de vegetação em APP. Pelotas, 2016

Figure 6 - Images of rural properties number 51 (a) and 61 (b), in the Registration Module CAR, with all delimited areas. Some areas with vegetation deficit in APP are featured. Pelotas, 2016
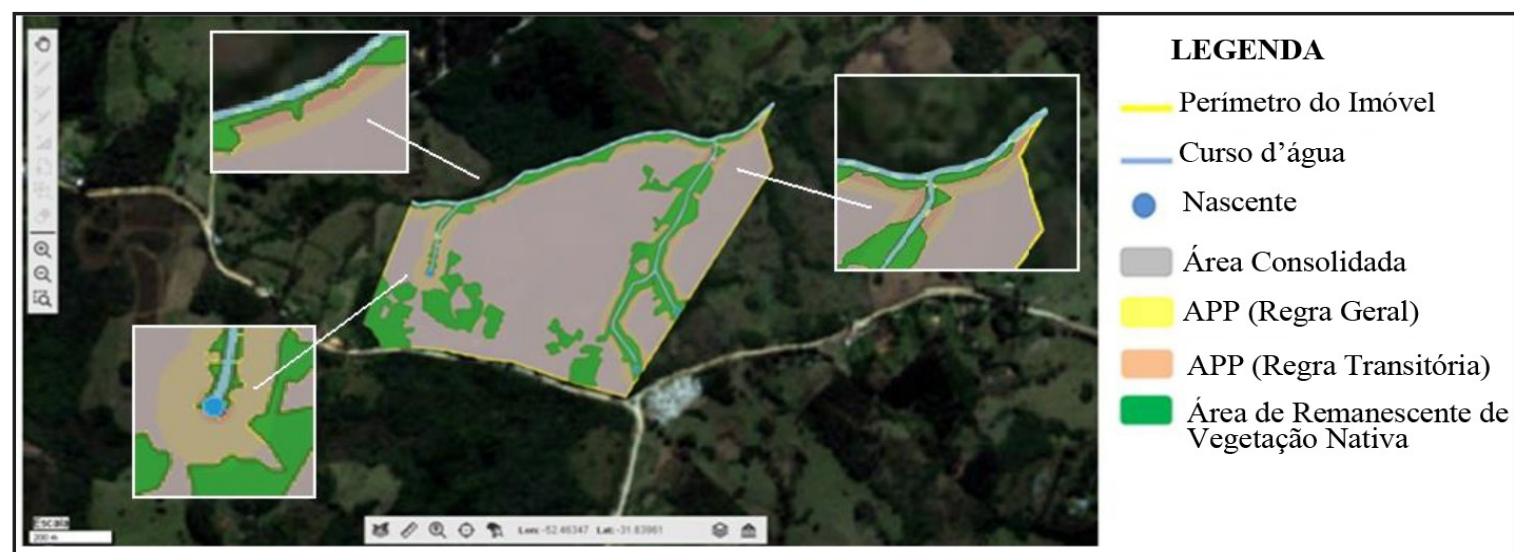

(a)

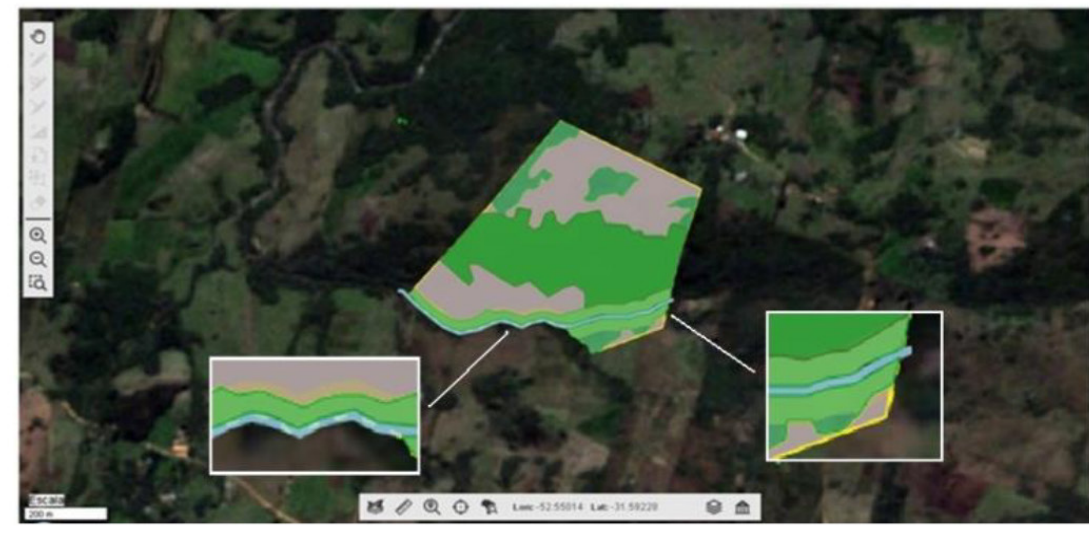

\section{LEGENDA}

Perímetro do Imóvel

- Curso d'água

$\square$ Área Consolidada APP (Regra Geral)

APP em Área de Remanescente de Vegetação Nativa

Área de Remanescente de Vegetação Nativa

Reserva Legal

(b)

Fonte: Autores (2016)

Para esse imóvel será obrigatória a recomposição da vegetação da APP de cada nascente em um raio mínimo de 15 (quinze) metros. Pelo imóvel medir 2,48 MF, ele terá que recompor a vegetação das faixas marginais de cada um dos quatro cursos d'água em 15 (quinze) metros (BRASIL, 2012 a, b). A área exigida de APP para a propriedade, segundo a regra geral do código 
vigente e do código antigo seria de 8,17 ha. Mas, por se tratar de APP em área consolidada, a exigência da vegetação será de 3,92 ha, resultando em uma perda de $52 \%$ da vegetação que antes era exigida.

No imóvel número 61 (Figura 6b), há uma grande quantidade de remanescente de vegetação nativa (caracterizada pela cor verde-clara), que foi dividido entre a Reserva Legal, a área de APP do curso d'água e em áreas sem destinação específica. Há um pequeno deficit de APP considerando-se a regra geral (representada pela cor amarela) e não há deficit de APP relativa às disposições transitórias (retratada pela cor coral), o que torna o imóvel rural adequado ambientalmente, segundo o Código Florestal vigente.

De acordo com a regra geral para essa propriedade, o curso d'água (largura até $10 \mathrm{~m}$ ) deveria ter $30 \mathrm{~m}$ de margens com vegetação para compor a APP. Considerando o tamanho do imóvel de 1,54 MF, e que ele se enquadra na regra transitória, as faixas marginais vegetadas para fins de APP devem ter 8 metros (BRASIL, $2012 \mathrm{a}$, b).

Ao contrapor a regra geral e a regra transitória do atual Código Florestal, é possível ver a significativa redução da área de vegetação exigida para composição das APP de cursos d'água e de nascentes e olhos d'água. Além disso, constata-se que o Código Florestal anterior propunha mais resguardo às APP, quando comparado com o código atual.

\section{Reserva Legal}

O total em área de remanescente de vegetação nativa das propriedades foi de 264,68 ha, sendo 163,46 ha usados para compor a vegetação de Reserva Legal dos imóveis avaliados. $\mathrm{Na}$ maioria das propriedades, a remanescente de vegetação nativa foi usada, para compor a Reserva Legal. A importância da existência da Reserva Legal vem do fato de que, por um lado, ela recupera áreas degradadas e garante a criação de corredores ecológicos e, por outro, garante o desenvolvimento sustentável dos proprietários rurais (OLIVEIRA; ROCHA; CARVALHO, 2014). É importante ressaltar que o uso de espécies exóticas interfere no papel de conservação da biodiversidade dessas áreas, pois não certifica a manutenção de suas aplicabilidades ecológicas (SILVA et al., 2012).

Foi possível averiguar que cerca de 70 imóveis têm RL com tamanho de $0 \%$ a $20 \%$ de sua área, e que quase 30 imóveis reservaram mais de $20 \%$ de suas vegetações nativas para constituir a RL. Sendo assim, grande parte dos imóveis está inferior aos $20 \%$ de Reserva Legal, abrangendo situações de ausência de RL na propriedade. Wollmann e Bastos (2014) constataram, em sua análise sobre a RL em imóveis rurais na região de Porto Alegre, RS, que as pequenas propriedades rurais averiguadas se encontraram dentro da legalidade, de acordo com o Novo Código Florestal, tendo em vista as Disposições Transitórias aplicadas. Contudo, no trabalho aqui apresentado, obteve-se uma porcentagem significativamente elevada de propriedades que estavam em desacordo com os $20 \%$ de RL.

A Lei no $4.771 / 65$ determinava a manutenção de $20 \%$ da propriedade como Reserva Legal, levando em conta o local estudado, sem importar a extensão do imóvel. A nova Lei no 12.651/12 desobriga os pequenos imóveis rurais com áreas consolidadas de restabelecer a reserva, acarretando maior impacto ao meio ambiente.

De acordo com o Sistema Nacional de Cadastro Rural (SNCR), mais de 90\% dos 5,1 milhões de imóveis rurais do Brasil tem até quatro módulos fiscais, correspondendo a $24 \%$ da extensão total das propriedades (135 milhões de hectares). Isso simboliza, pela regra transitória do atual Código Florestal, uma remição para $90 \%$ das propriedades rurais que até a data de 22 de julho de 2008 tiveram suas regiões de vegetação nativa suprimidas irregularmente (ASSOCIAÇÃO BRASILEIRA DE ENGENHARIA SANITÁRIA E AMBIENTAL, 2012).

De acordo com a regra geral do atual Código e do Código anterior, no qual ambos estipulam $20 \%$ da propriedade para RL, as 73 propriedades com valores abaixo de $20 \%$ de RL se encontrariam irregulares. Porém, como todos os 100 imóveis possuem até $4 \mathrm{MFs}$, todos estão 
regulares em relação ao novo código.

A recomposição da RL pode ser realizada com uso de vegetação exótica, contudo não deve exceder $50 \%$ da área total a ser recomposta. Já para imóveis de até 04 módulos fiscais, com remanescente de vegetação nativa menor que a prevista por lei, a RL deve ser composta pela área com vegetação nativa existente até 22 de julho de 2008, não permitindo novas conversões de uso do solo (BRASIL, $2012 \mathrm{a}, \mathrm{b}$ ).

As regiões de APP e de Reserva Legal estabelecidas nos pequenos imóveis rurais analisados foram reduzidas consideravelmente, quando equiparadas a Lei no 4.771/65 com a Lei no 12.651/12 (atual Código Florestal). Ocorre, então, que áreas substanciais de vegetação nativa de relevância para o meio ambiente não necessitarão mais serem restauradas.

\section{Conclusão}

O CAR configura uma conjuntura ímpar de estudo da disposição física dos imóveis rurais, dos seus recursos hídricos e vegetais. Em especial, simboliza a possibilidade de instrução dos proprietários sobre seus direitos e deveres ambientais.

Do total de 100 propriedades rurais avaliadas, $96 \%$ se encontram na zona rural, tendo elas, ao todo, área consolidada três vezes superior à sua área de remanescente de vegetação nativa. Tal contexto caracteriza o processo de desflorestamento recebido pelas propriedades rurais, gerado pela modificação das áreas de vegetação nativa em pastagens e em áreas agricultáveis. As zonas rurais são prenunciadoras das fontes dos corpos hídricos, e a intensificação do desmatamento dessas áreas tem, presumivelmente, reduzido a existência dos mananciais, de grande relevância para as regiões rural e urbana.

Todos os imóveis rurais cadastrados avaliados se molduram nas disposições transitórias do atual Código Florestal por serem pequenos imóveis rurais com presença de área consolidada. Desse modo, exclusivamente uma reduzida fração do total de imóveis está legalmente irregular. Ocorre, então, que a supressão dessa notável área vegetada que não carecerá ser reflorestada provoca extensivo impacto sobre os recursos ambientais e sobre a biodiversidade, ocasionando danos tanto à zona rural, quanto à zona urbana e aos seus moradores.

\section{Referências}

ASSOCIAÇÃO BRASILEIRA DE ENGENHARIA SANITÁRIA E AMBIENTAL. Impactos das alterações no Código Florestal. São Paulo, [2012]. Disponível em: http://abes-sp.org.br/arquivos/ impacto_alt_codflorestal.pdf. Acesso em: 11 jun. 2018.

AZEVEDO, L. F. de; FIALHO, M. A. V. "Florestamento" no pampa brasileiro: a visão dos pecuaristas familiares do território do Alto Camaquã/RS. Desenvolvimento e Meio Ambiente, Curitiba, v. 33, p. 209-224, abr. 2015.

AZEVEDO, R. E. S.; OLIVEIRA, V. P. V. Reflexos do novo código florestal nas Áreas de Preservação Permanente - APPs - urbanas. Desenvolvimento e Meio Ambiente, Curitiba, v. 29, p. 71-91, abr. 2014.

BRANCALION, P. H. S. et al. Análise crítica da lei de proteção da vegetação nativa (2012), que substitui o antigo Código Florestal: atualizações e ações em curso. Natureza e Conservação, Goiânia, v. 14, p. 1-15, mar. 2016. 
BRASIL. Lei n. 4.771, de 15 de setembro de 1965. Institui o Código Florestal. Diário Oficial da União, Brasília, DF, 19 set. 1965, retificado em 28 set. 1965. Disponível em: http://www.planalto. gov.br/ccivil_03/Leis/14771.htm. Acesso em: 11 jun. 2018.

BRASIL. Lei n. 11.326, de 24 de julho de 2006. Estabelece as diretrizes para a formulação da Política Nacional da Agricultura Familiar e Empreendimentos Familiares Rurais. Diário Oficial da União, Brasília, DF, 25 jul. 2006. Disponível em: http://www.planalto.gov.br/ccivil_03/_ ato2004-2006/2006/lei/111326.htm. Acesso em: 11 jun. 2018.

BRASIL. Lei n. 12.651, de 25 de maio de 2012. Dispõe sobre a proteção da vegetação nativa. Diário Oficial da União, Brasília, DF, 28 maio, 2012a. Disponível em: http://www.planalto.gov. br/ccivil_03/_ato2011-2014/2012/lei/112651.htm. Acesso em: 11 jun. 2018.

BRASIL. Lei n. 12.727, de 17 de outubro de 2012b. Altera a Lei no 12.651, de 25 de maio de 2012. Diário Oficial da União, Brasília, DF, 18 out., 2012b. Disponível em: http://www.planalto.gov.br/ ccivil_03/_ato2011-2014/2012/lei/L12727.htm. Acesso em: 11 jun. 2018.

BRASIL. Lei n. 13.887, de 17 de outubro de 2019. Altera a Lei no 12.651 , de 25 de maio de 2012, que dispõe sobre a proteção da vegetação nativa e dá outras providências. Diário Oficial da União, Brasília, DF, 18 out. 2019. Disponível em: https://www2.camara.leg.br/legin/fed/lei/2019/ lei-13887-17-outubro-2019-789278-publicacaooriginal-159243-pl.html. Acesso em: 14 nov. 2019.

BRASIL. Ministério da Agricultura, Pecuária e Abastecimento. Instituto Nacional de Colonização e Reforma Agrária. Índices básicos por município. [2013]. Disponível em: http://www.incra.gov. $\mathrm{br} / \mathrm{sites} / \mathrm{default} /$ files/uploads/estrutura-fundiaria/regularizacao-fundiaria/indices-cadastrais/ indices_basicos_2013_por_municipio.pdf. Acesso em: 12 dez. 2017.

BRASIL. Ministério da Agricultura, Pecuária e Abastecimento. Serviço Florestal Brasileiro. Cadastro Ambiental Rural. Boletim informativo. 2018. Disponível em: http://www.florestal. gov.br/documentos/car/boletim-do-car?format=html\&limit=20\&limitstart=0. Acesso em: 10 jun. 2018.

CAMPAGNOLO, K. et al. Área de preservação permanente de um rio e análise da legislação de proteção da vegetação nativa. Ciência Florestal, Santa Maria, v. 27, n. 3, p. 831-842, jul./set. 2017.

CHIAVARI, J.; LOPES, C. L. Os caminhos para a regularização ambiental: decifrando o novo código florestal. In: SILVA, A. P. M. da; MARQUES, H. R.; SAMBUICHI, R. H. R. (org.). Mudanças no Código Florestal Brasileiro: desafios para a implementação da nova lei. Rio de Janeiro: Ipea, 2016. p. 21-44.

CORDEIRO, L. A. M. et al. Integração lavoura-pecuária e integração lavoura-pecuária-floresta: estratégias para intensificação sustentável do uso do solo. Cadernos de Ciências \& Tecnologia, Brasília, v. 32, n. 1/2, p. 15-23, jan./ago. 2015.

CORREIA, M. L. A.; DIAS, E. R. Desenvolvimento sustentável, crescimento econômico e o princípio da solidariedade intergeracional na perspectiva da justiça ambiental. Revista Internacional de Direito Ambiental e Políticas Públicas, Macapá, n. 8, p. 63-80, dez. 2016.

DUTRA, M.; MÜLLER, J. Uso de Sistema de Informações Geográficas - SIG na avaliação dos impactos ambientais sobre o banhado do Rio dos Sinos no município de Campo Bom - RS. Revista de Iniciação Científica da ULBRA, Canoas, n. 15, p. 5-16, dez. 2017.

FEISTAUER, D. et al. Impactos do novo Código Florestal na regularização ambiental de propriedades rurais familiares. Ciência Florestal, Santa Maria, v. 24, n. 3, p. 749-757, jul./set. 2014.

FIDELIS, A.; APPEZZATO-DA-GLÓRIA, B.; PFADENHAUER, J. A importância da biomassa e das estruturas subterrâneas nos Campos Sulinos. In: PILLAR, V. de P. et al. (ed.). Campos sulinos: conservação e uso sustentável da biodiversidade. Brasília: MMA, 2009. p. 88-100. 
FOLLMANN, F. M.; FOLETO, E. M. Importância das áreas com vegetação na área de conservação natural do aquífero arenito basal Santa Maria, Santa Maria, RS. Boletim Goiano de Geografia, Goiânia, v. 33, n. 1, p. 37-51, jan./abr. 2013.

IBGE. Panorama da cidade de Pelotas. [2017]. Disponível em: https://cidades.ibge.gov.br/brasil/ rs/pelotas/panorama. Acesso em: 11 jun. 2018.

JAGUSZEWSKI, E. D.; GOTUZZO, C. C.; CONDORELLI, E. de M. F. Capacitação em cadastro ambiental rural: manual do treinando. Porto Alegre: SENAR - RS, 2014. p. 14-19.

LAUDARES, S. S. A.; SILVA, K. G.; BORGES, L. A. C. Cadastro ambiental rural: uma análise da nova ferramenta para regularização ambiental no Brasil. Desenvolvimento e Meio Ambiente, Curitiba, v. 31, p. 111-122, ago. 2014.

LEHFELD, L. S.; CARVALHO, N. C. B.; BALBIM, L. I. N. Código florestal: comentado e anotado. 3. ed. São Paulo: Método, 2015.

OLIVEIRA, A. L.; ROCHA, C. H. B.; CARVALHO, F. A. A reserva florestal legal: bases legais e análise de implantação no município de Juiz de Fora (MG) no período 2008-2010. Revista IberoAmericana de Ciências Ambientais, Aracaju, v. 5, n. 1, p. 47-65, jan./maio 2014.

PELOTAS. Lei n. 5.502, de 11 de setembro de 2008. Institui o Plano Diretor Municipal. Disponível em: http://sapl.camarapel.rs.gov.br/sapl_documentos/norma_juridica/1028_texto_ integral. Acesso em: 14 abr. 2018.

PEREIRA, V. C. Elementos para pensar a contribuição do Desenvolvimento Rural para conservação do bioma Pampa. Mundo Agrario, Buenos A̧res, v. 15, n. 28, p. 01-26, abr. 2014.

PINHEIRO, C. U. B. Matas ciliares e conservação das nascentes dos rios Anil, Bacanga e Tibiri, na Ilha de São Luís, Maranhão. Revista Brasileira de Geografia Física, Recife, v. 9, n. 4, p. 12121222, nov. 2016.

RIO GRANDE DO SUL. Decreto n. 52.431, de 23 de junho de 2015. Dispõe sobre a implementação do Cadastro Ambiental Rural. Diário Oficial do Estado, Porto Alegre, RS, 24 jun. 2015. Disponível em: http://www.sema.rs.gov.br/upload/arquivos/201610/14115105-decreto52431.pdf. Acesso em: 11 jun. 2018.

RIO GRANDE DO SUL. Ministério Público Estadual. TJ mantém liminar deferida em ação civil pública para proteção do Bioma Pampa. [2016]. Disponível em: https://www.mprs.mp.br/ noticias/ambiente/41865/. Acesso em: 11 jun. 2018.

RIO GRANDE DO SUL. Secretaria do Ambiente e Desenvolvimento Sustentável. [Website]. [2017]. Disponível em: http://www.sema.rs.gov.br/inicial. Acesso em: 11 jun. 2018.

RIO GRANDE DO SUL. Sistema de Cadastro Ambiental Rural. [2018]. Disponível em: http:// www.car.rs.gov.br/\#/site/consultar. Acesso em: jun. 2018.

RORIZ, P. A. C.; FEARNSIDE, P. M. A construção do Código Florestal Brasileiro e as diferentes perspectivas para a proteção das florestas. Novos Cadernos NAEA, Belém, v. 18, n. 2, p. 51-68, jun./set. 2015.

SILVA, C. A. Breve diagnóstico dos principais impactos ambientais de Pelotas. In: MELO, A. et al. Agenda 21 de Pelotas: construindo a cidadania ambiental. Pelotas: SQA; PMPel, 2004.

SILVA, J. A. A. et al (coord.). O código florestal e a ciência: contribuições para o diálogo. 2. ed. São Paulo: SBPC, 2012.

SILVA, R. G. et al. Avaliação do processo de restauração de área de preservação permanente degradada no sul de Minas Gerais. Revista em Agronegócio e Meio Ambiente, Maringá, v. 9, n. 1, p. 147-162, jan./abr. 2016. 
SOARES, A. B.; TROLEIS, A. L. Impactos ambientais na qualidade da água da nascente Pau Amarelo em Garanuns - PE. Revista de Geografia, Recife, v. 34, n. 3, p. 160-182, ago. 2017.

SUERTEGARAY, D. M. A.; SILVA, L. A. P. DA. Tchê Pampa: histórias da natureza gaúcha. In: PILLAR, V. de P. et al. (ed.). Campos sulinos: conservação e uso sustentável da biodiversidade. Brasília: MMA, 2009. p. 42-59.

TAMBOSI, L. R. et al. Funções eco-hidrológicas das florestas nativas e o Código Florestal. Estudos Avançados, São Paulo, v. 29, n. 84, p. 151-162, 2015.

TUPIASSU, L.; GROS-DESORMAUX, J-R.; CRUZ, G. A. C. Regularização fundiária e política ambiental: incongruências do cadastro ambiental rural no estado do Pará. Revista Brasileira de Políticas Públicas, Brasília, v. 7, n. 2, p. 188-203, ago. 2017.

VANZETTO, G. V. et al. Cadastro ambiental rural e avaliação comparativa entre o antigo e atual Código Florestal federal em um imóvel. Ciência e Natura, Santa Maria, v. 39, n. 2, p. 259-271, maio/ago. 2017.

VENZKE, T. S. Florística de comunidades arbóreas no município de Pelotas, Rio Grande do Sul. Rodriguésia, Rio de Janeiro, v. 63, n. 2, p. 571-578, abr./jun. 2012.

WOLLMANN, L. M.; BASTOS, L. C. Novo Código Florestal e reserva legal em propriedades rurais do município de Porto Alegre/RS. Ciência Rural, Santa Maria, v. 45, n. 3, p. 412-417, mar. 2014. 